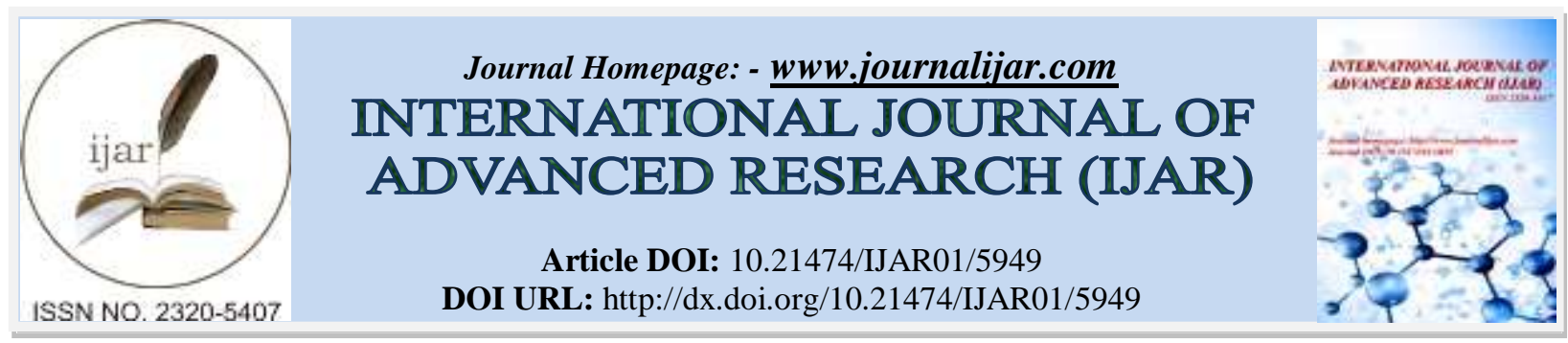

RESEARCH ARTICLE

\title{
A CLINICAL STUDY ON FUNDUS CHANGES IN PREGNANCY INDUCED HYPERTENSION PATIENTS ATTENDING A TERTIARY CARE HOSPITAL-VISAKHAPATNAM.
}

Dr. V. V. L. Narasimha Rao ${ }^{1}$, Dr. P. Manjula ${ }^{2}$ and Dr. Pradhana. Divya ${ }^{3}$.

1. M.S., D.O., Professor of Ophthalmology, Andhra medical college, Visakhapatnam.

2. M.S., D.O., Assistant Professor, Ophthalmology, Andhra medical college, Visakhapatnam.

3. MBBS, Junior Resident, Ophthalmology, Andhra medical college, Visakhapatnam.

\section{Manuscript Info}

Manuscript History

Received: 02 October 2017

Final Accepted: 04 November 2017

Published: December 2017

Key words:-

Pregnancy, Hypertension, Fundus.

\section{Abstract}

Aim: to study the fundus changes in patients with pih and to determine the correlation between fundus changes, blood pressure and severity of the disease. Methods: patients' clinical history with special importance to bp and proteinuria and visual complaints were recorded. Visual acuity recorded, anterior segment and fundus examination were done and graded accordingly, and the results obtained were analyzed. Results: of the 35 patients, no fundus changes were observed in 15 patients, 11 cases showed grade 1,6 cases showed grade 2 hypertensive changes.in 3 cases, central serous chorioretinopathy(cscr) were noted. 7 out of 13 patients with gestational hypertension,9 out of 13 patients of pre eclampsia 6 out of 9 patients of eclampsia presented with fundus changes. Conclusions: the retinal changes due to pih are significantly correlated with the severity of the disease and level of bp. Early diagnosis and treatment prevent further changes in the fundus.

Copy Right, IJAR, 2017,. All rights reserved.

\section{Introduction:-}

Hypertensive disorders during pregnancy are the world wide cause of mortality and morbidity in women. Pregnancy-induced hypertension (PIH) is categorized into different entities like gestational hypertension, chronic hypertension, pre eclampsia, eclampsia or pre-eclampsia super imposed on existing hypertension ${ }^{1}$.

Hypertension in pregnancy is defined as a systolic of $140 \mathrm{~mm} \mathrm{Hg}$ or greater or a diastolic of $90 \mathrm{~mm} \mathrm{Hg}$ or greater $^{(1)(2)}$. Gestational hypertension is elevated blood pressure, which develops after 20 weeks of gestation in a previously normotensive woman, though without proteinuria ${ }^{(1,2)}$

Preeclampsia include developing systolic blood pressure (SBP) $\geq 140$, or diastolic blood pressure (DBP) $\geq 90$, and proteinuria of 0.3 grams or greater in a 24-hour urine specimen after 20 weeks of gestation in a woman who was previously normotensive ${ }^{(1,2)}$. Eclampsia is the occurrence of convulsions or coma unrelated to other cerebral conditions, with signs and symptoms of pre- eclampsia ${ }^{(3)}$

Fundus changes in pregnancy-related hypertension occur as apart of the disease process where in the vascular endothelial dysfunction occurs, leading to vasospasm and capillary leaks ${ }^{(11)}$ 
Retinal changes that occur are mainly in correlation with the severity of hypertension. These changes are reversible most of the times ${ }^{(4,11)}$. As the blood pressure rises in pregnancy-induced hypertension, the effects of the BP are most easily seen in the fundus of the patients with PIH.

Hence the study is aimed at fundus examination of the patients with PIH, assessment of the retinal changes and determining the correlation between the fundus changes, blood pressure and the severity of the disease.

\section{Materials and methods:-}

In this observational cross-sectional study,35 patients with pregnancy-induced hypertension were included, which was carried out during October 2017 -november 2017 at tertiary care hospital, Visakhapatnam

\section{Exclusion criteria:-}

- Patients with previous history of hypertension, diabetes.

- Patients with any other posterior segment \& anterior segment pathology.

- Patients with the history of glaucoma and history of vitreo retinal surgery.

- Patients with gestational diabetes, cardio vascular complicating pregnancy, blood coagulating disorders, renal diseases were also excluded from the study.

\section{Methodology:-}

- Patients data such as name, age, Number of pregnancies, h/o abortions/still births, gestational age in weeks, blood pressure at the time of diagnosis, proteinuria (if any), were noted from the patient's records.

- Detailed ophthalmic history was taken regarding the complaints like blurring of vision, sudden loss of vision or previous such episodes, etc.,

- Patients visual acuity for far was noted using the Snellen chart.

- Examination of the anterior segment was done, and the pupil reactions were assessed. Tropicamide+phenylepherine eye drops were instilled in both eyes for the dilatation of the pupil. Posterior segment evaluation was done. The fundus findings were noted.

- The fundus findings were graded according to the Keith-Wegner classification ${ }^{(7)}$ into:

Grade I- mild generalized arterial attenuation, particularly of small branches;

Grade II-more severe grade I+focal arteriolar attenuation;

Grade III-grade II+haemorrhages, hard exudates, cotton wool spots;

Grade IV-grade III+optic disc swelling(papilledema) $)^{(7)}$.

- The severity of the PIH was classified as gestational hypertension, pre-eclampsia and eclampsia according to their clinical definitions.

Statistics: The data obtained was analyzed, and chi-square test was used. A p-value of $<0.05$ is taken as significant.

\section{Results:-}

- The mean age of the patients included in the study is 23.26 years. With the minimum age at 20years to the maximum at 27 years.

- Of the 35, 12 patients were primi gravida, and 23 were multi gravida, with gestational age ranging from 24 weeks to 38 weeks.

- 3 patients of 35 complained of gross fall of vision with sudden onset which persisted >2days.

- 12 patients complained of the transient loss of vision ranging from 3 min.-10minutes.

- 20 patients have no visual complaints.

- Of these patients with visual complaints, 13 were associated with headaches.

- 17 patients had PIH in their previous pregnancy. Of which 9 patients had the history of visual complaints and PIH during their previous pregnancies.

Of these patients, blood pressure recordings varied. 
Table 1:- Patients With Visual Symptoms For Varying Range Of Blood Pressure

\begin{tabular}{|l|l|l|}
\hline Blood pressure range & No.of patients & $\begin{array}{l}\text { No.of patients with visual } \\
\text { complaints }\end{array}$ \\
\hline $140 / 90-150 / 100$ & 14 & 3 \\
\hline $150 / 100-160 / 100$ & 15 & 7 \\
\hline$>160 / 100$ & 6 & 5 \\
\hline
\end{tabular}

Of the 35 patients, no fundus changes were observed in 15 patients,

- 11 cases showed grade 1 hypertensive changes

- 6 cases showed grade 2 hypertensive changes

- No cases were recorded with grade 3 and grade 4 cases

- In 3 cases, Central serous chorioretinopathy(CSCR) were noted.

Table 2:- Grades of PIH Fundus Changes

\begin{tabular}{|l|l|}
\hline Fundus changes noted & No. Of patients \\
\hline No changes & $13(37.14 \%)$ \\
\hline Grade 1 hypertensive changes & $11(31.42 \%)$ \\
\hline Grade 2 hypertensive changes & $8(22.81 \%)$ \\
\hline Grade 3 hypertensive changes & 0 \\
\hline Grade 4 hypertensive changes & 0 \\
\hline CSCR & $3(8 \%)$ \\
\hline
\end{tabular}

When correlated with the blood pressure and the fundus changes, the results varied.

Table 3:- Fundus Involvement For Different Range Of Blood Pressure Changes

\begin{tabular}{|l|l|l|l|}
\hline Blood pressure range & No.of patients & $\begin{array}{l}\text { No.of patients with fundus } \\
\text { changes }\end{array}$ & $\begin{array}{l}\text { No. Of patients with no fundus } \\
\text { changes }\end{array}$ \\
\hline $140 / 90-150 / 100$ & $14(40 \%)$ & 5 & 9 \\
\hline $150 / 100-160 / 100$ & $15(42.85 \%)$ & 11 & 4 \\
\hline$>160 / 100$ & $6(17.14 \%)$ & 6 & 0 \\
\hline
\end{tabular}

Fundus changes are correlating with the rise in blood pressure.

13 patients were diagnosed with gestational hypertension, 13 were with pre-eclampsia and 9 patients with eclampsia. When compared with the severity of the disease and the presence of fundus changes

TABLE 4:- Distribution of patients with fundus changes according to the severity of the disease.

\begin{tabular}{|l|l|l|}
\hline Category & No.of patients & No.of patients with fundus changes \\
\hline Gestational hypertension & $13(37.14 \%)$ & 7 \\
\hline Pre eclampsia & $13(37.14 \%)$ & 9 \\
\hline Eclampsia & $9(25.71 \%)$ & 6 \\
\hline
\end{tabular}

The results showed that as severity of the disease increased the presence of fundus changes also increased, this correlation is statistically significant.

\section{Discussion:-}

In this study there are about $66 \%$ multigravida patients and $34 \%$ of primi gravid, of these patients, gestational hypertension was diagnosed in $37.14 \%$, which is in equal percent to the pre-eclampsia patients. Eclampsia patients were less when compared to the above two categories in the severity of the disease.

Fundus changes due to PIH were noted in about $63 \%$ patients, and no changes were noted in the remaining $37 \%$ of the patients. Increased incidence of Fundus changes due to PIH was noted with increasing severity of the disease.

Fundus changes noted are grade 1 hypertensive changes in $31.4 \%$, grade 2 hypertensive changes in $22.8 \%$ whereas there are no patients with grade 3 and grade 4 changes. This may be due to early diagnosis of the disease and the immediate start of the treatment, as the patients included in the study were all the booked cases with regular ante natal check-ups. 
3 cases out of 35 cases showed reduced visual acuity, on fundus examination, CSCR was noticed in these cases. $34.28 \%$ cases complained about the transient blurring of vision and remaining $57.1 \%$ cases have no visual complaints.

Of the cases with no visual complaints, some cases have grade 1 or grade 2 hypertensive changes. Visual acuity is not effected in any of the above cases as there is no macular involvement in these cases.

When compared with the severity of the disease and presence of the fundus changes, the statistical significance is observed.

$40 \%$ of patients had 140/90 -150/100 mmHg blood pressure of which 5 patients had retinal changes.42.8\% had 150/100-160/100 mm of hg BP, of which 11 patients had fundus changes $17.1 \%$ had >160/100 $\mathrm{mmHg}$ BP, 7 of these patients had changes. Even though there is increases incidence of fundus changes with the increase in blood pressure, there are also cases with no retinal changes with that range of blood pressure.

In a study by Jaffe and Schatz ${ }^{[13]}$,it is reported that there is a significant correlation between the reduction in arteriole to vein ratio, number of focal arteriolar constrictions and severity of preeclampsia. They did not find any hemorrhages, exudates, cotton wool spots, or retinal detachment in their study of 17 mild preeclampsia and 14 severe preeclampsia patients., the present study has similar results to this study.

In a study of Reddy ${ }^{(12)}$ has reported retinal changes in $53.4 \%$ preeclampsia and in $71.2 \%$ in eclampsia patients, The most common fundus change was narrowing of arterioles. He found that retinal changes were significantly more in patients with severe hypertension. In the current study, there are more of gestational hypertensives and pre eclamptic patients compared to the above study, but the incidence of fundus changes with the severe hypertension is similar to the above study.

\section{Conclusion:-}

Visual symptoms are less in patients with PIH and are absent unless the macula is involved.

The retinal changes due to PIH are significantly correlated with the severity of the disease and level of blood pressure.

Early diagnosis and immediate treatment of the disease prevents further changes in the fundus.

Routine ophthalmoscopic examination of PIH cases for an assessment of the vascular changes should be done.Thereby the severity of the disease can be assessed, which is useful in the prevention of maternal morbidity and mortality.

\section{References:-}

1. Reem Mustafa, Sana Ahmed, Anu Gupta, and Rocco C. Venuto, "A Comprehensive Review of Hypertension in Pregnancy," Journal of Pregnancy, vol. 2012, Article ID 105918, 19 pages, 2012. doi:10.1155/2012/105918

2. E. J. Roccella, "Report of the National High Blood Pressure Education Program Working Group on High Blood Pressure in Pregnancy," American Journal of Obstetrics \& Gynecology, vol. 183, no. 1, pp. S1-S22, 2000.

3. Ocular manifestations of Pregnancy Induced Hypertension

4. Rahul Navinchandra Bakhda

5. Rachana, 2 New Gulabnagar Society, B/H Swaminarayan Temple, Raiya Road, Rajkot.

6. Reddy SC, Sivalingam N, Sheila Rani KG, Tham SW. Fundus changes in pregnancy induced hypertension. 2012; 5(6):694-697.

7. Mussey RD, Mundell BJ. Retinal examinations: A guide in the management of the toxic hypertensive syndrome of pregnancy. Am J Obstet Gynecol 1939; 37:30-36.

8. Hallum AV.Eye changes in hypertensive toxaemia of pregnancy. A study of three hundred cases. JAMA 1936; 106:1649-51.

9. Wagner HP.Arterioles of the retina in toxemia of pregnancy. JAMA 1933; 101:1380-4.

10. Sheie HG.Evaluation of ophthalmoscopic changes in hypertension and arteriolar sclerosis. Arch Ophthalmol $1953 ; 49: 117-38$. 
11. Klein R, Klein BE, Moss SE, Wang $\mathrm{Q}$ et al. Hypertension and retinopathy, arteriolar narrowing and arteriovenous nicking in a population. Arch Ophthalmol 1994; 112:92-8. http://hyper.ahajournals.org/content/44/4/442.full

12. Ashton N,Harry J.The pathology of cotton wool spots and cystoids bodies in hypertensive retinopathy and other diseases. Trans Ophthalmol Soc UK 1963; 83:91.

13. Richard RO. Pregnancy induced hypertension (preeclampsiaecclampsia). In: Schachat AP, Murphy RB (eds), 2nd ed, St. Louis, Mosby, 1994:1405-1412.

14. Reddy SC. Ocular fundus changes in toxemia of pregnancy. Am J Ophthalmology 1989;86(7): 367-372

15. Fundus changes in pregnancy-induced hypertension Jaffe G, Schatz H. ocular manifestations of preeclampsia. The Antiseptic 1987;103(3 Pt1):309-315 http://pubmedcentralcanada.ca/pmcc/articles/PMC3530810/ 